Graduate Student; Population, Health and Wellness

\title{
Depression in patients with spinal injury in Qatar: \\ a mixed-methods study
}

Badriya Al Shamari, Graduate Public Health student, Qatar University Dr. Lily O'Hara, Associate Professor of Public Health, Qatar University

\section{Introduction}

Spinal injury

- A life-threatening traumatic event

- Associated with devastating health burden

Spinal injury causes medical problems and severe physical disability

- Loss of motor, sensory, neurological functions

- Physical and physiological complications Negative influence on health and performance of daily living activities

Middle East: $\sim 15$ cases per million every year

\section{Qatar}

- 1.25 spinal injuries per 100,000 yearly

- In 2010, $12 \%$ of with spinal injury patients treated in Hamad Hospital and Rumailah Hospital; increased rate $17.2 \%$ by 2013

In Qatar, depression is the most common mental disorder

$25 \%-30 \%$ of spinal injury patients experience significant depressive symptoms associated with:

- Lack of social support

- Sociodemographic factors

- Cultural factors

- Prolonged rehabilitation process

Limited studies on mental health after spinal injury

- Available evidence show high prevalence of depression

- Few studies assess depression and spinal injury in Arab Gulf region

- Association between depression and spinal injury has not been yet established in Qatar

\section{Aim}

* To explore the issue of depression in hospital patients with spinal injury in Qatar

\section{Objectives}

1. Determine the prevalence of depression in hospital patients with spinal injury

2. Determine the association between the level of depression and cause and site of spinal injury, sociodemographic factors, and social support in hospital patients with spinal injury

3. Explore the experiences of depression in hospital patients with spinal injury

\section{Methods}

\section{Study design}

- Cross-sectional mixed methods study

- Fully mixed methods concurrent equal status design

Qualitative and quantitative methods incorporated in all aspects of the design, were conducted concurrently, and had equal value to the study

\section{Population}

$\mathrm{N}=106$ patients admitted between 1 January $2020-30$ December 2020

- Hamad General Hospital (Trauma, and Neurological) Inpatient Units, TICU, Trauma Stepdown, Trauma OPD and Qatar Rehabilitation Institute Inpatient Unit and Outpatient)

Inclusion criteria: Males and females; 18 - 65 years; conscious and able to communicate; inpatient and outpatient (recently acquired spinal cord/ column injuries; traumatic and nontraumatic)

Exclusion criteria: patients with confused state, critical condition, inability to give informed consent, past psychiatric history of depression, and previous suicidal attempts or if injury resulted from suicidal attempt

Data collection methods

- Patients approached two weeks after admission

- Interviewer administered questionnaire and semi-structured interview

Data collection instruments

O Sociodemographic characteristics

Patient Health Questionnaire (PHQ-9)

Social Support Survey

Semi-structured interview guide

\section{Results}

1 Demographic characteristics

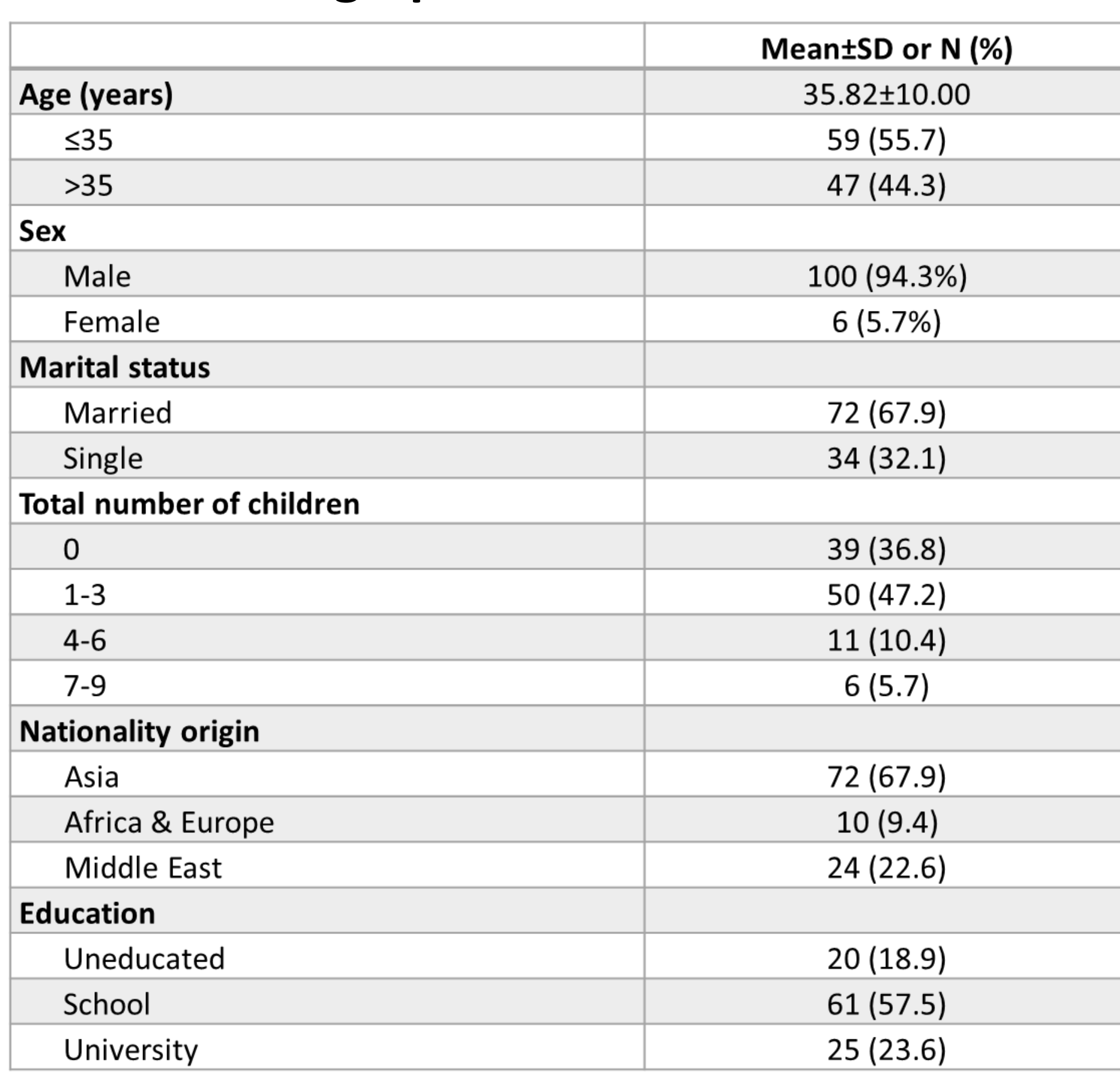

Social support

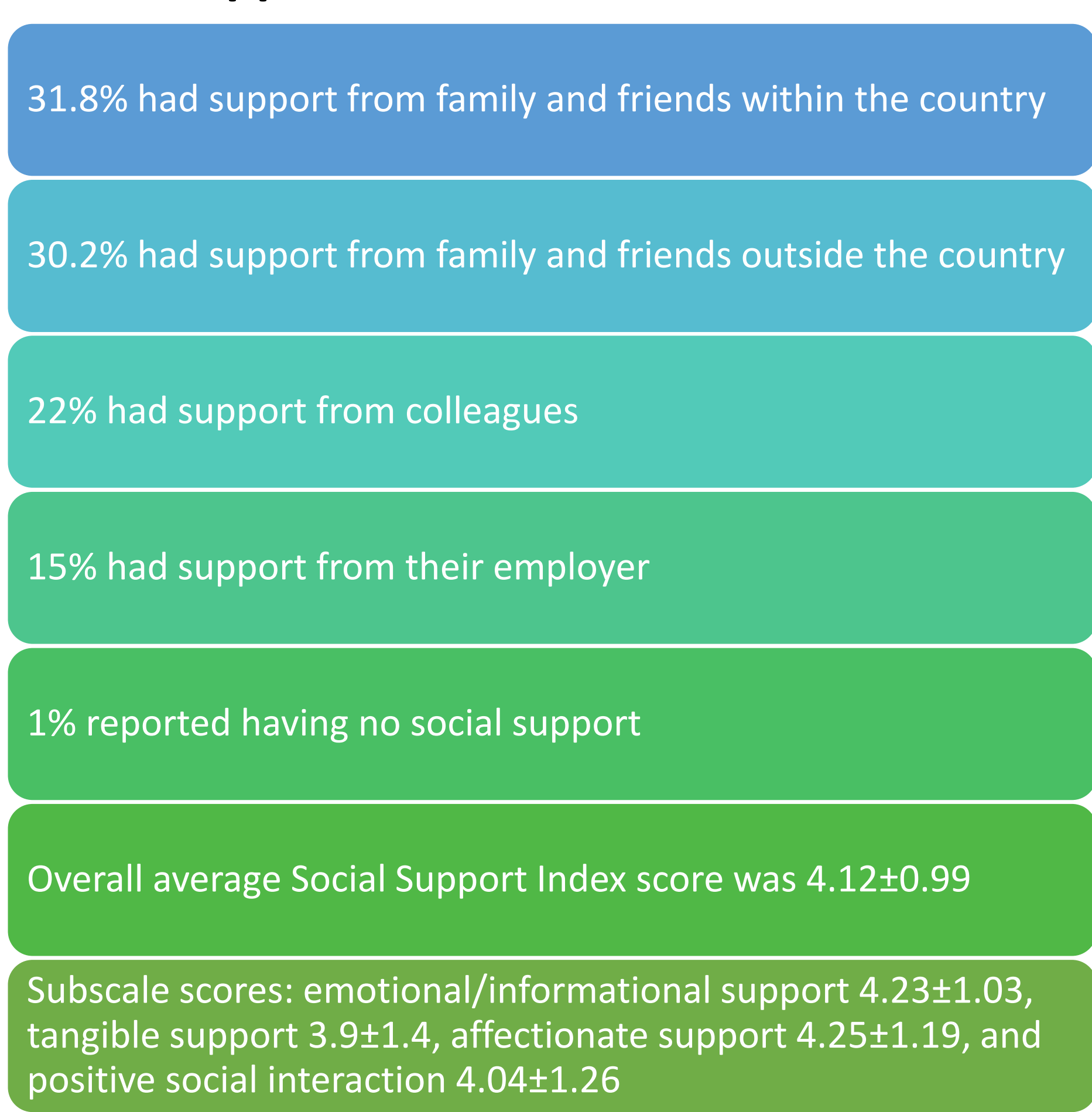

Table 2 Depression and cause of injury

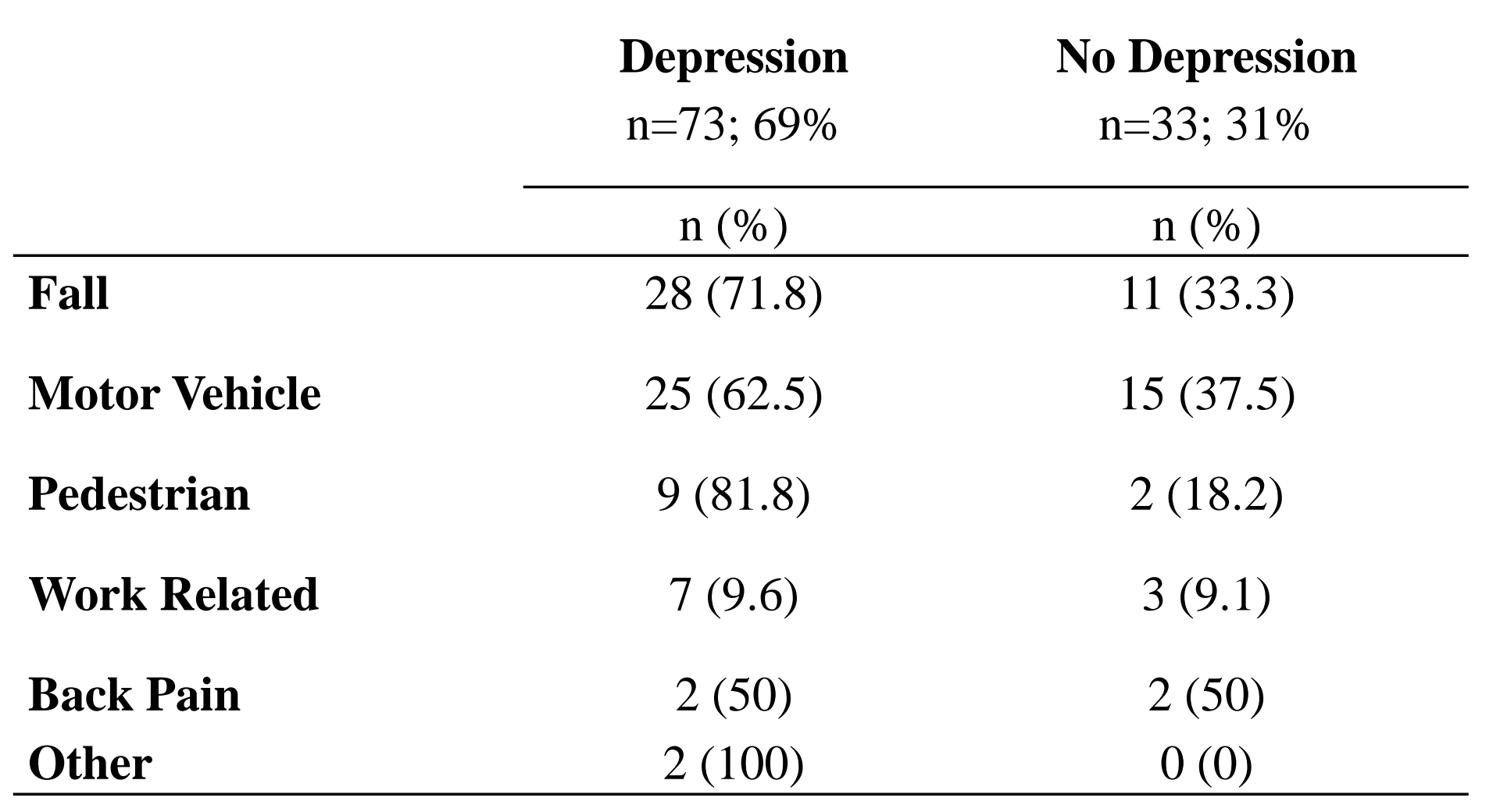

Other $2(100)$

Table 3 Depression and sociodemographics

\begin{tabular}{|c|c|c|c|}
\hline & $\begin{array}{l}\text { Depression } \\
\mathrm{N}=73 ; 69 \% \\
\end{array}$ & $\begin{array}{c}\text { No Depression } \\
\mathrm{N}=33 ; 31 \%\end{array}$ & $P$ value \\
\hline & & & \\
\hline Age & & & 0.27 \\
\hline$\leq 35$ & $38(64)$ & $21(36)$ & \\
\hline$>35$ & $35(75)$ & $12(25)$ & \\
\hline Gender & & & 0.09 \\
\hline Male & $67(67)$ & $33(33)$ & \\
\hline Female & $6(100)$ & 0 & \\
\hline Nationality & & & 0.20 \\
\hline Asia & $46(64)$ & 26 (36) & \\
\hline Africa \& Europe & $7(70)$ & $3(30)$ & \\
\hline Middle East & $20(83)$ & $4(17)$ & \\
\hline Education & & & 0.99 \\
\hline School & $42(69)$ & $19(31)$ & \\
\hline University & $17(68)$ & $8(32)$ & \\
\hline Uneducated & $14(70)$ & $6(30)$ & \\
\hline Number of childrer & & & 0.095 \\
\hline No children & 28 (72) & $11(28)$ & \\
\hline 1-3 children & $33(66)$ & $17(34)$ & \\
\hline 4-6 children & 10 (91) & 1 (9) & \\
\hline 7-9 children & $2(33)$ & $4(67)$ & \\
\hline Marital status & & & 0.79 \\
\hline Married & $49(68)$ & $23(32)$ & \\
\hline Single & $24(71)$ & $10(29)$ & \\
\hline
\end{tabular}

\section{Conclusion}

- Depression is prevalent among patients with spinal injury

- Depression is associated with social and spiritual support

- Results are expected to:

Contribute to the quality of clinical care and rehabilitation of patients with spinal injury through

- Highlight the need for policies to ensure the early detection, referral and treatment of depression, and enhance social support for people with spinal injuries

\section{References}

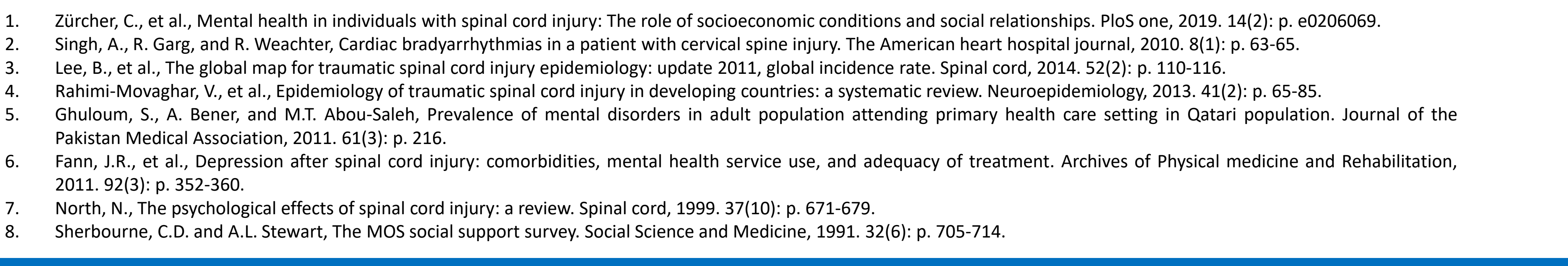

